\title{
๑ OS LIMITES À LIBERDADE DE EXPRESSÃO NA ERA DA (DES)INFORMAÇÃO: NOVAS FRONTEIRAS E PERSPECTIVAS PARA A EFETIVAÇÃO DOS DIREITOS FUNDAMENTAIS
}

\section{THE LIMITS OF FREEDOM OF EXPRESSION IN THE (DES)INFORMATION AGE: NEW FRONTIERS AND PERSPECTIVES FOR THE REALIZATION OF FUNDAMENTAL RIGHTS}

Antonio Leal de Oliveira Faculdade de Direito de Vitória (FDV) Doutor em Teoria do Estado e Direito Constitucional (PUC-Rio) e em Direito Público (Paris Nanterre) Vitória/ Espírito Santo / Brasil antonio.leal.oliveira@gmail.com

\author{
Carolina Rondelli do Nascimento \\ Faculdade de Direito de Vitória (FDV) \\ Graduanda em Direito (FDV) \\ Vitória / Espírito Santo / Brasil \\ carolinarondellin@gmail.com \\ (iD Carolina Marcondes Fraga \\ Faculdade de Direito de Vitória (FDV) \\ Graduanda em Direito (FDV) \\ Vitória / Espírito Santo / Brasil \\ carolinamarcondesfraga@gmail.com
}

Resumo: O presente artigo objetiva analisar possíveis limites ao Direito Fundamental à liberdade de expressão, devido polêmicas contemporâneas envolvendo a sua colisão com outros direitos, sobretudo a dignidade humana. Assim, identifica-se a necessidade de mitigar a difusão de discursos ofensivo à dignidade da pessoa como um parâmetro importante para tal limitação. Busca-se demonstrar os impactos provocados na vida de indivíduos e grupos, pela utilização irrestrita da liberdade de expressão, no contexto da "Era da informação". Como metodologia utilizou-se o método hipotético-dedutivo, a partir de pesquisas bibliográfica e da análise de exemplos práticos de discursos ofensivos à dignidade humana. Como resultado a ser alcançado, pretende-se apresentar a forma como o Estado Democrático de Direito brasileiro trata essa questão de forma a se buscar meios, principalmente jurídicos, para se mitigar os efeitos desta.

Palavras-chave: liberdade de expressão; discurso ofensivo à dignidade da pessoa; colisão de direitos fundamentais.

Abstract: This article aims to analyze which should be the limits of the Fundamental Right to freedom of expression, due to contemporary controversies involving its collision with other rights, mainly the human dignity. Thus, the need to mitigate the dissemination offensive speech to the dignity of the person is an important parameter for this limitation. For that reason, we seek to demonstrate what are the impacts caused on the lives of individuals and groups, due to the unrestricted use of freedom of expression, especially in the context of the "Information 
OLIVEIRA, Antonio Leal de; NASCIMENTO, Carolina Rondelli do; FRAGA, Carolina Marcondes. Os limites à liberdade de expressão na era da (des)informação: novas fronteiras e perspectivas para a efetivação dos direitos fundamentais

Age". The methodology was exercised from the hypothetical deductive method, carried out from bibliographic research and analysis of practical examples of violations of dignity, based on offensive speeches. As a result to be achieved, it is intended to present the way Brazilian rule of Law deals with this issue in order to seek means, mainly legal, to mitigate the effects of this.

Keywords: freedom of expression; offensive speech to the dignity of the person; collision between fundamental rights.

Para citar este artigo (ABNT NBR 6023:2018)

OLIVEIRA, Antonio Leal de; NASCIMENTO, Carolina Rondelli do; FRAGA, Carolina Marcondes. Os limites à liberdade de expressão na era da (des)informação: novas fronteiras e perspectivas para a efetivação dos direitos fundamentais. Revista Thesis Juris - RTJ, São Paulo, v. 10, n. 2, p. 187-203, jul./dez. 2021. http://doi.org/10.5585/rtj.v10i2.16930.

\section{Introdução}

"Quem fala confirma o poder da palavra". Esse interessante trecho da música "O Segundo Sol”, na versão da banda Baiana System, serve de mote inicial para a proposta desse artigo. Isso porque, ao se transpor o referido trecho à contemporaneidade brasileira, percebe-se que, na verdade, quem mais percebe o poder da palavra não é aquele que fala, mas sim aquele sobre quem se fala.

Por isso, o que se defende neste artigo é que o ordenamento jurídico deve, na maioria dos casos, colocar o direito à honra, à imagem e à dignidade acima da liberdade de expressão. Afinal, aqueles sobre quem se fala são, em geral, o público mais afetado pela proliferação de discursos que violam a dignidade da pessoa, que se difundem mais facilmente quando se entende que esses são permitidos sob a égide da liberdade de expressão desarrazoada.

Portanto, com o intuito de estabelecer em linhas mais detidas quais seriam os limites da liberdade de expressão, realiza-se uma subdivisão na análise do tema, dividindo-o em dois enfoques: teórico e jurídico.

Adota-se o método hipotético-dedutivo, motivo pelo qual parte-se da premissa de que há necessidade de limitação da liberdade de expressão quando essa é utilizada para proferir discursos ofensivos à dignidade humana e, para verificar a sua validade, recorre-se à pesquisa bibliográfica e à análise de casos concretos.

Sendo assim, no primeiro capítulo, realiza-se uma contextualização histórica, a fim de demonstrar como os objetivos da limitação da liberdade de expressão transformaram-se com o passar do tempo. Adiante, esclareceu-se porque os discursos ofensivos à dignidade da pessoa 
OLIVEIRA, Antonio Leal de; NASCIMENTO, Carolina Rondelli do; FRAGA, Carolina Marcondes. Os limites à liberdade de expressão na era da (des)informação: novas fronteiras e perspectivas para a efetivação dos direitos fundamentais

devem sofrer limitações por meio da responsabilização jurídica dos ofensores. Para isso, a partir de casos contemporâneos emblemáticos e de renomados teóricos, analisou-se os impactos dos discursos de ódio nos indivíduos, nos grupos e na sociedade como um todo.

Já no segundo capítulo, efetua-se abordagem essencialmente jurídica, apontando de quais limites à liberdade de expressão já estão normatizados no Direito brasileiro. Ademais, a partir de uma interpretação sistemática do ordenamento jurídico, analisou-se a colisão entre o Direito Fundamental à liberdade de expressão e à dignidade humana, investigando qual deve prevalecer.

Em suma, a relevância deste artigo também é evidenciada pelo seguinte trecho da supramencionada canção: “antes que eu visse, você disse e eu não pude acreditar". Isso porque o enorme impacto provocado pelas palavras transmitidas nas redes nem sempre são sentidos pelo indivíduo de forma imediata, especialmente por estarmos inseridos na Era da (des)informação. Por esse motivo, uma prévia resposta político-institucional adequada faz-se essencial.

\section{$1 \mathrm{O}$ discurso ofensivo à dignidade da pessoa enquanto fronteira à liberdade de expressão}

A fim de demonstrar que o entendimento de que a liberdade de expressão permite largamente a proliferação de discursos ofensivos à dignidade humana é indesejável, tanto do ponto de vista moral como jurídico, inicia-se com uma contextualização histórica. Adiante, esclarecer-se-á qual deve ser o limite da liberdade de expressão para, então, analisarmos os impactos desse tipo de discurso nos indivíduos, nos grupos e na sociedade como um todo.

O maior temor quando se fala em limitar a liberdade de expressão é que, por meio desta limitação, poderes autoritários silenciem críticas e pontos de vista minoritários, conforme ocorreu no Brasil durante o período da Ditadura Militar. Porém, o objetivo de limitar a liberdade de expressão na contemporaneidade, felizmente, não é mais esse.

Em uma retrospectiva histórica, constata-se que a maioria dos filósofos liberais que defendem com vigor a liberdade de expressão, como Voltaire e John Stuart Mill, escreveram numa época na qual o Estado a limitava visando manter o seu poder, silenciando críticas e perspectivas distintas. Da mesma forma, os constituintes brasileiros positivaram a liberdade de expressão como uma reação aos abusos ocorridos durante a Ditadura Militar.

Contudo, esse momento histórico marcado pela relação conflituosa entre Estado e liberdade de expressão, de modo que a última seria um óbice ao primeiro, foi superado no Brasil. A Constituição de 1988 prevê, no artigo $5^{\circ}$, incisos IV e IX, o direito fundamental à 
OLIVEIRA, Antonio Leal de; NASCIMENTO, Carolina Rondelli do; FRAGA, Carolina Marcondes.

Os limites à liberdade de expressão na era da (des)informação: novas fronteiras e perspectivas para a efetivação dos direitos fundamentais

liberdade de expressão, além de prever valores importantes como o pluralismo político e ideológico. Nesse sentido, Rosane da Silva, Bárbara Bolzan e Paula Cigana (2019, p. 220) ressaltam que:

\begin{abstract}
A liberdade de expressão é considerada um direito fundamental no atual ordenamento jurídico nacional. Após o triste período de ditadura, onde o direito de expressar ideias foi tolhido, o Brasil consagrou, no artigo $5^{\circ}$, incisos IV e IX, da Constituição Federal, este tão importante direito. Desta forma, pretende o ordenamento jurídico nacional possibilitar as múltiplas expressões, individuais e coletivas, no seio de uma sociedade tão plural como a brasileira. Como não poderia deixar de ser, atualmente, qualquer tentativa de reprimir ou censurar a livre manifestação de ideias é vista como grave afronta, e, especialmente, violação que deve ser prontamente combatida. (grifo nosso)
\end{abstract}

Assim, quando se fala em limitar a liberdade de expressão atualmente, o objetivo, em geral, não é mais consolidar o poder daqueles que governam e as opiniões dominantes. Muito pelo contrário: a limitação ainda é feita pelo Estado, mas para proteger os cidadãos, principalmente aqueles em condições de vulnerabilidade, interferindo nos conflitos advindos da relação entre indivíduos e liberdade de expressão. Esse contexto é ainda mais alarmante considerando a popularização da internet, cuja propagação de conteúdo, por vezes, afronta direitos de outros, caracterizando um exercício de liberdades que extrapolam os limites e atingem garantias e princípios tão caros ao ordenamento brasileiro (SILVA; BOLZAN; CIGANA, 2019, p. 221).

Percebe-se assim que não se intenta mais proteger o Estado das palavras dos cidadãos, em uma relação vertical, mas sim alguns cidadãos das palavras de outros, em uma relação horizontal. Para isso, um importante limite à liberdade de expressão são os discursos que ofendem a dignidade da pessoa.

Quando da conclusão de seu artigo "A Liberdade de Expressão e o Problema do 'Hate Speech", Daniel Sarmento (2009, p. 96) reconhece ser correto, tanto do ponto de vista moral como jurídico, o caminho adotado pelo Brasil, que aceita as restrições à liberdade expressão a fim de combater o preconceito e a intolerância contra minorias estigmatizadas.

Essa restrição também nos parece devida, sendo que algumas manifestações de intolerância são conhecidas, no Direito Internacional, como "hate speech" - em português, discursos de ódio. Nessa perspectiva, cabe ressaltar que os discursos de ódio figuram como um exemplo de discursos que ofendem a dignidade da pessoa, de forma que os discursos de ódio sempre serão ofensivos à dignidade da pessoa, mas nem toda manifestação ofensiva à dignidade será tratada como discurso de ódio.

Para uma melhor conceituação, tem-se a definição construída por Riva de Freitas e Matheus de Castro (2013, p. 344), a qual atribui como elemento central do discurso de ódio: 
OLIVEIRA, Antonio Leal de; NASCIMENTO, Carolina Rondelli do; FRAGA, Carolina Marcondes. Os limites à liberdade de expressão na era da (des)informação: novas fronteiras e perspectivas para a efetivação dos direitos fundamentais

\begin{abstract}
A expressão do pensamento que desqualifica, humilha e inferioriza indivíduos e grupos sociais. Esse discurso tem por objetivo propagar a discriminação desrespeitosa para com todo aquele que possa ser considerado "diferente", quer em razão de sua etnia, sua opção sexual, sua condição econômica ou seu gênero, para promover a sua exclusão social.
\end{abstract}

Esse discurso responsável por inferiorizar indivíduos ou grupos sociais não consegue ter o seu poder minado apenas com manifestações individuais e isoladas a esse contrárias. Isso porque, em uma análise do contexto social em que a liberdade de expressão está inserida, notase, muitas vezes, uma enorme disparidade entre as posições de quem fala e de quem deseja ser ouvido. Esse contraste de posições dentro de uma sociedade demonstra o quanto tais relações são assimétricas.

Essas relações assimétricas, marcadas por desigualdades não só econômicas, como também sociais, são produtos do que Pierre Bourdieu (2004) chama de "dominação simbólica", que torna sutis tais desigualdades, que deveriam ser evidentes, e se perfaz de maneira tal que os interesses particulares se apresentam como interesses universais, o que consequentemente gera uma violência simbólica, já que exercida sem coação física, mas psíquica.

Desse modo, a falta de consciência das classes que não detém o poder simbólico, ou seja, daquelas que se encontram sob o domínio simbólico da classe dominante e, por conseguinte, legitimam a ordem estabelecida, propicia a manipulação dos meios de comunicação em proveito da cultura dominante, como atesta Bourdieu (2004, p.11) em sua obra "O Poder Simbólico":

As relações de comunicação são de modo inseparável, sempre, relações de poder que dependem, na forma e no conteúdo, do poder material ou simbólico acumulado pelos agentes (ou pelas instituições) envolvidos nessas relações e que, como o dom ou o potlatch, podem permitir acumular poder simbólico.

Dessa forma, quando um indivíduo ou grupo que detém grande capital social pretende exercer sua liberdade de expressão amplamente frente a outro indivíduo ou grupo, de maneira que cause prejuízo àqueles que são dominados, evidencia-se a necessidade de amparo estatal às minorias. A título de exemplo, destaca-se o caso Danilo Gentili, humorista que ofendeu a deputada federal Maria do Rosário em sua conta no Twitter com as seguintes palavras: "cínica, falsa e nojenta".

Gentili possui mais de 17 milhões de seguidores em seu perfil na referida rede social, enquanto Maria do Rosário possui um pouco mais de 300 mil, o que evidencia o abismo entre o alcance das publicações dele e o das publicações dela. Dessa maneira, está configurada a dominação simbólica por parte do humorista sobre a deputada na medida que seu discurso de ofensa legitima e incentiva que outras pessoas que o seguem reproduzam o mesmo 
OLIVEIRA, Antonio Leal de; NASCIMENTO, Carolina Rondelli do; FRAGA, Carolina Marcondes. Os limites à liberdade de expressão na era da (des)informação: novas fronteiras e perspectivas para a efetivação dos direitos fundamentais

comportamento, perpetuando a desigualdade e assimetria das relações, uma vez que Gentili, detentor de um maior poder simbólico, influencia a população com o intuito de desmoralizar Maria do Rosário, que, por sua vez, não consegue se defender.

Ademais, Maria do Rosária afirmou perante autoridade judicial que Danilo causou um dano concreto, quando disse agressivamente que lhe daria um soco, o que serviu de amparo para que outras pessoas também a ameaçassem, o que reforça que a ideia de que a liberdade de expressão desenfreada de um, suprime a liberdade de expressão de outro.

\subsection{Os discursos ofensivos na Era da (des)informação}

Percebe-se, no referido caso, o quanto o espaço cibernético intensifica os impactos de formas de expressão voltadas à humilhação de indivíduos e de grupos. Posto isso, não há como debater liberdade de expressão sem levar em consideração os meios de comunicação predominantes e as plataformas pelas quais os indivíduos efetivamente utilizam para se expressarem. No entanto, essas plataformas nem sempre oferecem as informações dotadas da devida procedência. O comportamento humano nesse sentido tem se mostrado complacente ao compartilhamento em larga escala de opiniões, supostos fatos e informações ainda que não saibam da real origem e dos fundamentos que as constroem. Desse modo, torna-se questionável se vivemos na era da informação ou, em um olhar mais crítico, da desinformação.

Nessa ótica, é possível caracterizar a sociedade brasileira através da perspectiva de Hannah Arendt sobre a sociedade de massas - aquela que é composta por pessoas moldadas ideologicamente para agir de maneira massificada, ou seja, uniforme e irrefletidamente.

Assim, os meios mais modernos de comunicação acabam sendo uma plataforma poderosa e, possivelmente nefasta, para que pessoas ou movimentos aproveitem para disseminar ideologias e padrões de comportamento ou costumes que em muitos casos podem afetar, ainda que indiretamente, minorias e indivíduos. Para tanto é necessário que pessoas se comportem da forma supracitada, descrita por Arendt.

Tal comportamento massificado se reflete em situações concretas e até amplamente conhecidas no meio social, como foi o caso da atriz Cléo Pires. O caso aconteceu em outubro de 2019, quando noticiou-se o ganho de cerca de 20 quilos no peso da atriz, o que a fez fugir de um padrão estético que é convencionado pela sociedade como o ideal, ainda que a própria pessoa não compactue. Após a publicação da notícia a atriz passou a ser atacada em suas redes sociais com críticas e ofensas dotadas de um preconceito odioso. Ao se deparar com tais críticas, a atriz questionou a motivação das pessoas que foram em massa para suas redes sociais ofendê- 
OLIVEIRA, Antonio Leal de; NASCIMENTO, Carolina Rondelli do; FRAGA, Carolina Marcondes. Os limites à liberdade de expressão na era da (des)informação: novas fronteiras e perspectivas para a efetivação dos direitos fundamentais

la. A resposta veio dos mesmos internautas, que novamente de forma massiva declaram que "se está na internet podemos comentar", "você é uma figura pública e tem de estar sujeita à tais críticas”, dentre outras alegações $(\mathrm{G} 1,2019)$.

Urge ressaltar que a referida situação envolveu uma atriz, o que trouxe proporções maiores para as ofensas. Contudo, esse tipo de situação ocorre diariamente com todos os tipos de pessoas. Mais uma vez, o que se vê são indivíduos utilizando-se do argumento da liberdade de expressão passaram a agir de forma agressiva, injuriando e ofendendo. Há de se distanciar a injúria e a ofensa do direito à liberdade de expressão.

Não obstante à questão dessa lógica de massificação social, é possível associar o fenômeno que assola o Brasil à chamada tese da Sociedade do Espetáculo, tese elaborada pelo pensador marxista Guy Debord (2003), que define a ideia de espetáculo surge como instrumento para unificar a sociedade de massas, através da relação social entre as pessoas, interposta pela imagem passada para elas através da mídia, sendo importante a interpretação predominante que se dá ao fato e não ao fato em si.

Tal fenômeno é uma forma obscura e implícita de dominar o imaginário popular através da alienação: "Não é somente pela sua hegemonia econômica que a sociedade portadora do espetáculo domina regiões subdesenvolvidas. Domina-as enquanto sociedade do espetáculo" (DEBORD, 2003, p. 39).

Quando certas situações são expostas em uma sociedade de espetáculo, a imagem é que tem maior valor. Nota-se que a interpretação majoritária acerca do fato em muitas vezes é pautada por "achismo" e senso comum, apenas por ser mais interessante que o próprio acontecimento em si. Nesse cenário, até as mentiras e falácias ganham força pois são mais atraentes para o cidadão médio que a real procedência da informação, o que pode causar consequências negativas para a vida de indivíduos ou grupos sociais.

Um exemplo em que a espetacularização social trouxe consequências negativas para uma pessoa foi o caso da estudante de psicologia Alinne Araújo, que em sua rede social narrava sua luta contra depressão e ansiedade. O ocorrido foi que no dia de seu casamento a jovem foi abandonada no altar por seu noivo, após muito esforço para conseguir juntar dinheiro suficiente para fazer a festa. Não bastasse a dor pelo abandono, passou-se a circular na internet o boato de que a jovem teria traído o ex-noivo, o que prontamente foi negado por ela, e inclusive pelo rapaz, o que não impediu que muitas pessoas fossem nas redes sociais da jovem proferir ofensas, se justificando novamente com a ideia de "posso dizer o que quiser". Alinne se suicidou um dia depois. 
OLIVEIRA, Antonio Leal de; NASCIMENTO, Carolina Rondelli do; FRAGA, Carolina Marcondes.

Os limites à liberdade de expressão na era da (des)informação: novas fronteiras e perspectivas para a efetivação dos direitos fundamentais

Como demonstrado no caso supracitado, a "sociedade do espetáculo" vitimou de forma irreparável uma jovem, pois as pessoas se viram no direito de ofendê-la de forma gratuita e passando longe de qualquer tipo de empatia, tendo em vista a frágil condição psicológica da jovem, protagonizou esse vergonhoso "espetáculo".

Por outro lado, ressalta-se que há casos nos quais, ainda que o indivíduo sinta-se ofendido por determinado discurso na internet, não se mostra adequado limitar a liberdade de expressão. Elementos como a vulnerabilidade do atingido e o intuito das palavras proferidas devem ser analisados. Colnago (2016) traz, em sua tese de doutorado, traz um importante exemplo de situação na qual a liberdade de expressão deve prevalecer:

Também há que se considerar que a Internet é o meio por excelência de difusão da
expressão, sobretudo quando se trate de crítica a agentes públicos. Não se pode, na
confusão entre público e privado tão infelizmente comum no Brasil, interpretar
críticas à atuação de agentes públicos como ofensas à honra ou à sua imagem. Por
uma questão de proporcionalidade, a expressão neste caso deve ser a mais livre
possível, mesmo que parcialmente violadora de uma certa concepção alargada de
honra e imagem, na medida em que a crítica feita à atuação do agente, ainda que
equivocada, contribui para jogar luzes e foco sobre determinado tema que pode ser de
interesse público.

A reflexão que se coloca é: até que ponto a liberdade de expressão irrestrita e usada de forma irresponsável é benéfica para as pessoas? Sobretudo em uma sociedade do espetáculo e massificada como é a atual conjuntura brasileira. No fim, o que se conclui é que não é saudável para o bem-estar social a autonomia para dizer tudo que pensa sem que haja qualquer tipo de responsabilização, inclusive jurídica pelos atos lesivos aos direitos de outrem. Nesse sentido, torna-se claro que o excesso à liberdade de expressão merece as devidas respostas jurídicoinstitucionais

\subsection{Do caráter pedagógico da resposta jurídica}

A importância de respostas jurídicas e institucionais aos discursos ofensivos à dignidade da pessoa pode ser pensada a partir do chamado "paradoxo da tolerância", desenvolvido pelo filósofo britânico Karl Popper, em sua obra “A Sociedade Aberta e Seus Inimigos”, cujo cerne encontra-se insculpido na seguinte afirmativa: a tolerância ilimitada leva ao desaparecimento da própria tolerância. Isso porque, segundo Popper (1994, p.44), se estendermos a tolerância ilimitada até mesmo aos intolerantes, 
OLIVEIRA, Antonio Leal de; NASCIMENTO, Carolina Rondelli do; FRAGA, Carolina Marcondes. Os limites à liberdade de expressão na era da (des)informação: novas fronteiras e perspectivas para a efetivação dos direitos fundamentais

\begin{abstract}
Os tolerantes serão destruídos e a tolerância com eles. Nessa formulação, não insinuo, por exemplo, que devamos sempre suprimir a expressão de filosofias intolerantes; desde que possamos combatê-las com argumentos racionais e mantê-las em xeque frente a opinião pública, suprimi-las seria, certamente, imprudente. Mas devemos nos reservar o direito de suprimi-las, se necessário, mesmo que pela força; pode ser que eles não estejam preparados para nos encontrar nos níveis dos argumentos racionais, mas comecemos por denunciar todos os argumentos; eles podem proibir seus seguidores de ouvir os argumentos racionais, porque são enganadores, e ensiná-los a responder aos argumentos com punhos e pistolas. Devemos, então, reservar, em nome da tolerância, o direito de não tolerar o intolerante. (grifo nosso).
\end{abstract}

Nesse sentido, percebe-se que se deve buscar um equilíbrio entre responder o mal com o mal, ou seja, a intolerância com a intolerância; e deixar de responder o mal, de modo a tolerar os intolerantes. Constata-se, então, que a responsabilização dos intolerantes pela ordem jurídica é o equilíbrio perfeito.

Por um lado, o julgamento perante um tribunal faz com que não haja negligência da sociedade frente a atos intolerantes, tendo como efeito a dissuasão e a simbolização do repúdio estatal aos discursos de ódio. Por outro, essa responsabilização não é intolerante, pois no devido processo legal há sempre espaço ao contraditório e a sentença dada pelo juiz, devendo ser fundamentada, é extremamente pedagógica.

Exemplo nítido desse caráter pedagógico ocorreu no estado do Espírito Santo, em 2016, quando o jovem Lázaro Nascentes Dias postou na internet que teve relações sexuais com Izabela Stelzer. A jovem de 22 anos ingressou com uma ação e o juiz determinou que Lázaro deveria publicar um texto em seus perfis, tanto do Facebook como do Instagram, se retratando a respeito do havia dito. Logo, ele foi responsabilizado pelo o que fez e teve de expressar arrependimento, o que com certeza foi pedagógico e tem poder de dissuasão para que outros não façam o mesmo.

Diante dessas considerações, conclui-se ser devida a responsabilização jurídica daqueles que proferem discursos que ofendem a dignidade. Retomando a canção de Cássia Eller, a luta é para que não só o poder da palavra seja descoberto, mas principalmente para que a fala seja, como diz o trecho anterior da música, uma maneira de cura, e não mais de humilhação.

\title{
2 Da normatização dos limites da Liberdade de Expressão e sua ponderação com outros Direitos Fundamentais
}

O Direito Fundamental à liberdade de expressão é inquestionavelmente importante na contemporaneidade, eis que, na "era da (des)informação", a ideia de manifestar os seus pensamentos publicamente já se tornou uma prática comum adotada pela sociedade. Diante desse raciocínio, apesar desse direito ser considerado um dos mais essenciais para nossa vida, 
OLIVEIRA, Antonio Leal de; NASCIMENTO, Carolina Rondelli do; FRAGA, Carolina Marcondes.

Os limites à liberdade de expressão na era da (des)informação: novas fronteiras e perspectivas para a efetivação dos direitos fundamentais

algumas importantes questões precisam ser sanadas acerca dessa garantia, retomando a reflexão supra: até que ponto pode-se expressar livremente um pensamento de forma a não ferir o direito do outro? Ou seja, qual é o limite jurídico da liberdade de expressão?

A liberdade de expressão é um direito fundamental tutelado por nossa Carta Magna e tema de relevante valor para o direito e para sua própria construção. Por isso mereceu destaque no texto constitucional, de modo que a $\mathrm{CF} / 88 \mathrm{em}$ seu Art.5 $5^{\circ}$, IX dispôs que: "é livre a expressão da atividade intelectual, artística, científica e de comunicação, independentemente de censura ou licença". Assim, segundo Farias (2001, p.45) a liberdade de expressão se trata da "faculdade de manifestar livremente os próprios pensamentos, ideias, opiniões, crenças, juízos de valor, por meio da palavra oral e escrita, da imagem ou de qualquer outro meio de difusão".

É importante destacar também que esse direito faz parte para a construção de um Estado Democrático de Direito, pois pressupõe a garantia de que todos possam expressar livremente seus pensamentos sem se preocupar com uma censura prévia. Este direito está diretamente ligado a natureza da pessoa humana e da forma como os indivíduos relacionam e interagem entre si. Em seu sentido amplo a liberdade de expressão se trata de um:

Conjunto de direitos relacionados às liberdades de comunicação, que compreende: a liberdade de expressão em sentido estrito (ou seja, de manifestação do pensamento ou de opinião), a liberdade de criação e de imprensa, bem como o direito de informação. (TÔRRES, 2003, p. 74)

Entretanto, é necessário nos atentar que a mesma Constituição Federal, em seu art. $5^{\circ}$, IV, disciplina o seguinte: "É livre a manifestação do pensamento, sendo vedado o anonimato". Pela redação deste artigo fica claro que a própria Constituição Federal impõe a primeira limitação ao direito da liberdade de expressão, ficando claro assim que essa garantia não se trata de um direito pleno e ilimitado.

Além disso, a liberdade de expressão não é um direito absoluto e encontra limites entre outros direitos fundamentais. Não se pode falar em liberdade irrestrita se há ofensa à dignidade da pessoa humana, princípio fundamental para um Estado Democrático de Direito. Por isso, não se pode afirmar que todos possam expressar livremente seus pensamentos e opiniões a qualquer custo. Quando um direito correr risco frente a outro deve-se haver ponderação de valores. Diante dessa ideia, Fernandes (2011, p. 279) destaca que: 
OLIVEIRA, Antonio Leal de; NASCIMENTO, Carolina Rondelli do; FRAGA, Carolina Marcondes. Os limites à liberdade de expressão na era da (des)informação: novas fronteiras e perspectivas para a efetivação dos direitos fundamentais

\begin{abstract}
Nesses termos, para a doutrina dominante, falar em direito de expressão ou de pensamento não é falar em direito absoluto de dizer tudo aquilo ou fazer tudo aquilo que se quer. De modo lógico-implícito a proteção constitucional não se estende à ação violenta. Nesse sentido, para a corrente majoritária de viés axiológico, a liberdade de manifestação é limitada por outros direitos e garantias fundamentais como a vida, a integridade física, a liberdade de locomoção. Assim sendo, embora haja liberdade de manifestação, essa não pode ser usada para manifestação que venham a desenvolver atividades ou práticas ilícitas (antissemitismo, apologia ao crime etc...)
\end{abstract}

É muito comum na sociedade atual o abuso do direito (considerado ato ilícito pelo art. 187 do Código Civil) da liberdade de expressão por meio de tecnologias de comunicação em massa, especialmente com a popularização da internet, visto que as pessoas utilizam as redes sociais muitas das vezes para dizer o que pensam, reproduzindo opiniões de influenciadores digitais ou utilizando suas próprias ideias, a fim de que seus argumentos possam ganhar credibilidade a partir de seus seguidores que o apoiam, sem se preocupar nas consequências negativas que aquela ofensa possa acarretar na vida do ofendido.

Além disso, cabe ressaltar que muitos utilizam a internet para se manifestar contra certas pessoas ou ideias acreditando que estejam no anonimato, imaginando que a internet seja uma “terra sem lei”. Na realidade estão cometendo um ato ilícito, passível de responsabilização e identificação do infrator. Nesse sentido, destaca-se o advento da Lei Geral de Proteção de Dados, que disciplina a liberdade de expressão no ambiente virtual, atribuindo responsabilidade civil aos controladores, conforme art. 42 da referida legislação, em caso de não retirarem conteúdo ofensivo de suas plataformas após decisão judicial, conhecido como "notice and take down".

Ainda que a liberdade de expressão seja um direito fundamental, muitas vezes é utilizado como um mecanismo de promoção de políticas ilícitas, tais como os discursos homofóbicos e racistas, incitação à violência, intolerância religiosa, calúnia, difamação e injúria, tanto que o legislador penal positivou os crimes contra a honra nos artigos 138, 139 e 140 do Código Penal, o que reforça, novamente, que a liberdade de expressão não é um direito absoluto, pois encontra limites até mesmo legais.

Não resta dúvida de que a liberdade de expressão e de opinião são os direitos mais preciosos da humanidade, pois todo o cidadão tem o direito de falar, escrever, publicar e disseminar livremente a sua opinião, mas existe a ressalva de responder pelo abuso desta liberdade nos casos previstos em lei, como por exemplo nos assuntos que se referem a utilização desse direito para ferir a honra e a imagem do indivíduo, sendo esses casos passiveis de punição.

Vale ainda ressaltar que o pacto internacional de Direitos Civis e Políticos que se trata de uns dos três instrumentos que constituem a Carta Internacional dos Direitos Humanos a qual 
OLIVEIRA, Antonio Leal de; NASCIMENTO, Carolina Rondelli do; FRAGA, Carolina Marcondes.

Os limites à liberdade de expressão na era da (des)informação: novas fronteiras e perspectivas para a efetivação dos direitos fundamentais

o Brasil é signatário, já previa uma relativização ao direito da liberdade de expressão conforme o seu artigo 19 disciplinando que todas as pessoas tem o Direito da Liberdade de expressão, porém isso implicará deveres e responsabilidades especiais que consequentemente acarretarão em certas restrições, como aqueles que envolvem assegurar o respeito dos direitos e da reputação das demais pessoas e proteger a segurança nacional, a ordem, a saúde ou a moral pública.

Deve-se tratar o tema de forma a contemplar a situação fática analisada sob os ensejos de uma interpretação sistemática do Direito. Ou seja, compreender que o ordenamento jurídico é complexo e coeso, na medida que uma específica matéria não pode ser observada sem a consciência da necessidade de analisá-la contida em um conjunto de normas, em um sistema amplo, o que deve ser levado em consideração quando da ponderação de direitos fundamentais.

\subsection{Da ponderação de direitos fundamentais}

Compreendido que nenhum direito ou princípio é absoluto, já que todos estão submetidos a barreiras, que devem formar esse sistema jurídico complexo, impondo limites ao exercício exagerado e lesivo de uma faculdade, vale reafirmar que não se nega o caráter fundamental do direito à liberdade, mas sim há de se compreender que, assim como qualquer direito, existem responsabilidades a serem observadas por quem utiliza dessa garantia fundamental.

Liberdade é um direito primordial e de difícil conceituação. As enormes e extensas formas de manifestar tal direito tornam complicado delimitar o que, de fato, seria esta prerrogativa. Robert Alexy (2008, p. 222) busca tratar da conceituação da liberdade, também reconhecendo seu caráter de subjetividade e vagueza:

O conceito de liberdade é, ao mesmo tempo, um dos conceitos práticos mais fundamentais e menos claros. Seu âmbito de aplicação parece ser quase ilimitado. Quase tudo aquilo que, a partir e algum ponto de vista, é considerado como bom ou desejável é associado ao conceito de liberdade.

O sistema de direitos fundamentais e princípios não trata de hierarquizar os ditos pressupostos de existência do homem, mas entende que estes direitos devem entrelaçar-se, buscando limites em no próprio sistema. Ou seja, há de se aceitar que o sistema jurídico, especificamente em seus direitos fundamentais e princípios, os conflitos devem ser sanados levando em consideração a sistematicidade do ordenamento e, consequentemente a utilização de outros direitos ou princípios como óbice ao abuso de uma faculdade. 
OLIVEIRA, Antonio Leal de; NASCIMENTO, Carolina Rondelli do; FRAGA, Carolina Marcondes. Os limites à liberdade de expressão na era da (des)informação: novas fronteiras e perspectivas para a efetivação dos direitos fundamentais

Robert Alexy cita Günter Dürig, importante jurista alemão, com grandes influências no Direito Constitucional, explanando o entendimento de Dürig sobre o sistema de valores e pretensões, este que tratava de classificar os direitos fundamentais com base em suas especificidades e seus valores no sistema constitucional:

\begin{abstract}
O sistema de valores e pretensões de Dürig pode ser considerado como um modelo de direitos fundamentais em três níveis. No primeiro nível está a dignidade humana, como 'princípio constitucional supremo'. No segundo nível encontram-se, de um lado, o direito geral de liberdade como 'principal direito de liberdade' e, de outro, o direito geral da igualdade como 'principal direito de igualdade'. No terceiro nível, por fim, estão os direitos de liberdade e igualdade específicos. (DÜRIG apud ALEXY, 2008, p. 372)
\end{abstract}

A dignidade humana, como direito supremo e pressuposto existencial, pode atuar como óbices ao extremado uso das liberdades, portanto. Temos a dignidade como valor supremo, não no sentido de estar hierarquicamente acima dos demais direitos e princípios, mas sim, na medida em que a dignidade é além de mínimo existencial, um controle sobre outras atitudes que firam os direitos personalíssimos. A dignidade é valor tão importante que é positivada na Constituição Brasileira de 1988 como sendo um dos fundamentos da República Federativa do Brasil.

Art. 1. ${ }^{\circ}$ A República Federativa do Brasil, formada pela união indissolúvel dos Estados e Municípios e do Distrito Federal, constitui-se em Estado Democrático de Direito e tem como fundamentos:

$[\ldots]$

III - a dignidade da pessoa humana;

Tanto a liberdade quanto a dignidade humana são tratados de forma expressa na forma de norma constitucional. Analisar uma questão envolvendo conflito entre estes direitos ou princípios é extremamente complexa e não se deve buscar formas objetivas para tratar e tais lides. Por si só, o sistema é subjetivo. Isso, porém, não o torna falho nem omisso, mas sim, reforça o caráter complexo do sistema jurídico nacional. A ponderação valorativa é, então, a forma mais eficaz de tratar destes conflitos, observando a especificidade de cada caso.

A dignidade, em exposição de Alexy quando cita Dürig, detêm maior peso em face de outros princípios. Como já dito, o exercício teórico do jurista não fala em hierarquização destes princípios, mas uma forma de sopesar os direitos ou princípios que colidem entre si, em situações conflitantes e extraordinárias.

Compreender a dignidade da pessoa humana como fundamento da República Federativa do Brasil é um importante passo inicial para se entender que a dignidade é um direito fundamental de extremada importância, principalmente para solucionar casos em que se mostram conflitantes dois princípios ou direitos fundamentais. Não há de se falar aqui em 
OLIVEIRA, Antonio Leal de; NASCIMENTO, Carolina Rondelli do; FRAGA, Carolina Marcondes.

Os limites à liberdade de expressão na era da (des)informação: novas fronteiras e perspectivas para a efetivação dos direitos fundamentais

censura, em proibição da livre expressão, mas sim na compreensão de que para um direito, há a responsabilidade. E que em um Estado Democrático de Direito há de se estabelecer relações entre princípios, normas e valores.

A jurisprudência pátria é repleta de situações que tratam do conflito entre a liberdade de expressão e a dignidade da pessoa. $\mathrm{O}$ entendimento dos tribunais superiores, nestes casos de conflitos, demonstra uma compreensão certeira quanto a necessidade de adotar elementos de ponderação no caso concreto, analisando a lide de acordo com suas especificidades.

RECURSOS ESPECIAIS. RESPONSABILIDADE CIVIL. 1. REPARAÇÃO POR DANOS MORAIS. OBRA LITERÁRIA. FIGURA PÚBLICA. ABUSO DO DIREITO DE EXPRESSÃO E DE INFORMAÇÃO. AFRONTA AOS DIREITOS DE PERSONALIDADE. EXISTÊNCIA. INFORMAÇÃO INVEROSSÍMIL. EXISTÊNCIA DE ANIMUS INJURIANDI VEL DIFFAMANDI. 2. QUANTUM INDENIZATÓRIO. MÉTODO BIFÁSICO. OBSERVÂNCIA DOS PRINCÍPIOS DA PROPORCIONALIDADE E DA RAZOABILIDADE. 3. DIREITO À RETRATAÇÃO. PRINCÍPIO DA REPARAÇÃO INTEGRAL. PUBLICAÇÃO DA DECISÃO CONDENATÓRIA. POSSIBILIDADE. 4. RECURSO ESPECIAL DOS RÉUS DESPROVIDO. RECURSO ESPECIAL DO AUTOR PARCIALMENTE PROVIDO. 1. Liberdade de expressão e de informação em contraponto à proteção aos direitos da personalidade. O Superior Tribunal de Justiça estabeleceu, para situações de conflito entre tais direitos fundamentais, entre outros, os seguintes elementos de ponderação: a) o compromisso ético com a informação verossímil; b) a preservação dos chamados direitos da personalidade, entre os quais incluem-se os direitos à honra, à imagem, à privacidade $\mathrm{e}$ à intimidade; e c) a vedação de veiculação de crítica jornalística com intuito de difamar, injuriar ou caluniar a pessoa (animus injuriandi vel diffamandi). 1.1. A princípio, não configura ato ilícito as publicações que narrem fatos verídicos ou verossímeis, embora eivados de opiniões severas, irônicas ou impiedosas, sobretudo quando se trate de figuras públicas que exerçam atividades tipicamente estatais, gerindo interesses da coletividade, e a notícia e a crítica referirem-se a fatos de interesse geral relacionados à atividade pública desenvolvida pela pessoa noticiada. 1.2. Não obstante a liberdade de expressão seja prevalente, atraindo verdadeira excludente anímica, ela não é absoluta, devendo ser balizada pelos demais direitos e princípios constitucionais. Comprovado, na espécie, que o autor do livro ultrapassou a informação de cunho objetivo, deve preponderar os direitos da personalidade. Dano moral configurado. 2. O valor estabelecido pelas instâncias ordinárias a título de danos morais somente deve ser revisto por esta Corte Superior nas hipóteses em que a condenação se revelar irrisória ou excessiva, em desacordo com os princípios da razoabilidade e da proporcionalidade. No caso, a tríplice função da indenização por danos morais e o método bifásico de arbitramento foram observados, de acordo com a gravidade e a lesividade do ato ilícito, de modo que é inviável sua redução. 3. O direito à retratação e ao esclarecimento da verdade possui previsão na Constituição da República e na Lei Civil, não tendo sido afastado pelo Supremo Tribunal Federal no julgamento da ADPF 130/DF. O princípio da reparação integral (arts. 927 e 944 do CC) possibilita o pagamento da indenização em pecúnia e in natura, a fim de se dar efetividade ao instituto da responsabilidade civil. 3.1. Violada a expectativa legítima, cabe à jurisdição buscar a pacificação social, podendo o Magistrado determinar a publicação da decisão condenatória nas próximas edições do livro. 4. Recurso especial dos réus desprovido. Recurso especial do autor parcialmente provido. (STJ - REsp: 1771866 DF 2017/0118809-2, Relator: Ministro MARCO AURÉLIO BELLIZZE, Data de Julgamento: 12/02/2019, T3 - TERCEIRA TURMA, Data de Publicação: DJe 19/02/2019) (grifo nosso) 
OLIVEIRA, Antonio Leal de; NASCIMENTO, Carolina Rondelli do; FRAGA, Carolina Marcondes. Os limites à liberdade de expressão na era da (des)informação: novas fronteiras e perspectivas para a efetivação dos direitos fundamentais

Observadas essas premissas, visualiza-se com maior clareza a necessidade de se observar cada caso, sob os ensejos de uma interpretação e ponderação valorativa, compreendendo que, diante de conflitos entre a dignidade da pessoa humana e a liberdade de expressão, abre-se espaço para um julgamento baseado em uma ótica sistematizada do Direito.

\section{Conclusão}

Conclui-se a partir da leitura deste artigo que, do ponto de vista ético e jurídico, quando discursos ofensivos à dignidade implicarem em violações ao direito à honra e à imagem de indivíduos ou grupos, a liberdade de expressão deve sofrer limitações, realizadas a partir de respostas político-institucionais.

Constata-se que a limitação da liberdade de expressão não encontra amparo jurídico para ter como objetivo o silenciamento de críticas aos governos e de pontos de vista minoritários, conforme ocorreu no Brasil durante o período da Ditadura Militar. Assim, na contemporaneidade, essa limitação visa proteger os indivíduos de discursos ofensivos à dignidade da pessoa difundidos no interior da própria sociedade.

Nesse contexto, a importância de respostas jurídicas a discursos notavelmente violadores da dignidade humana consiste em dois aspectos principais: a) na assimetria das relações sociais, de modo que a resposta do ofendido, tendo ele menos poder simbólico do que aquele que profere o discurso violador, seria insuficiente; e b) o contexto da era da (des)informação, na qual há uma ampla difusão de conteúdos nefastos a indivíduos ou grupos.

Além disso, verifica-se quais limites à liberdade de expressão estão previstos no Direito brasileiro. Inicialmente, não se pode falar em liberdade irrestrita se há ofensa à dignidade da pessoa humana, princípio fundamental para um Estado Democrático de Direito. Nessa lógica, adotando uma interpretação sistemática do ordenamento jurídico, tem-se que quando um direito correr risco frente a outro deve-se haver ponderação de valores.

Assim, aponta-se alguns dos limites à liberdade de expressão já normatizados: a Constituição Federal, em seu art. $5^{\circ}$, IV, impõe o anonimato como limitação à manifestação do pensamento; a Lei Geral de Proteção de Dados, que disciplina a liberdade de expressão no ambiente virtual, atribui responsabilidade civil aos controladores s conforme art. 42 da referida legislação, em caso de não retirarem conteúdo ofensivo de suas plataformas após decisão judicial, conhecido como "notice and take down"; e a calúnia, difamação e injúria, são crimes contra a honra previstos nos artigos 138, 139 e 140 do Código Penal. 
OLIVEIRA, Antonio Leal de; NASCIMENTO, Carolina Rondelli do; FRAGA, Carolina Marcondes. Os limites à liberdade de expressão na era da (des)informação: novas fronteiras e perspectivas para a efetivação dos direitos fundamentais

Em suma, vê-se que, apesar de inexistir uma hierarquização pré-determinada e generalizada entre os direitos fundamentais em questão, deve-se analisar cada caso em particular. Nessa ponderação, frisa-se a necessidade de se limitar, por meio do poder políticoinstitucional, discursos que, em nome da liberdade de expressão, violam a dignidade humana um dos fundamentos de nossa República.

\section{Referências}

ALEXY, Robert. Teoria dos direitos fundamentais. Tradução de Virgílio Afonso da Silva. São Paulo: Malheiros Editores, 2008.

BOURDIEU, Pierre. O poder simbólico. 5. ed. Rio de Janeiro, RJ: Bertrand Brasil SA, 2004.

BRASIL. Constituição [da] República Federativa do Brasil. São Paulo: Saraiva, 2007.

BRASIL. Decreto no ${ }^{\circ}$ 592, de 6 de julho de 1992. Diário Oficial [da] República Federativa do Brasil, Poder Executivo, Brasília, DF, 7 jul. 1992. Disponível em:

http://www.planalto.gov.br/ccivil_03/decreto/1990-1994/d0592.htm. Acesso em: 15 out. 2019.

BRASIL. Decreto-Lei 2.848, de 07 de dezembro de 1940. Código Penal. Diário Oficial da União, Rio de Janeiro, 31 dez. 1940.

BRASIL. Lei n. 10.406, 10 de janeiro de 2002. Código Civil. Diário Oficial da União, Rio de Janeiro, 11 jan. 2002.

BRASIL. Superior Tribunal de Justiça. REsp: 1771866 DF 2017/0118809-2. Relator: Ministro Marco Aurélio Belizze. Data de Julgamento: 12/02/2019. T3 - TERCEIRA TURMA. Data de Publicação: DJe 19/02/2019.

COLNAGO, Cláudio de oliveira santos. Liberdade de expressão na internet: desafios regulatórios e parâmetros de interpretação. 2016. Tese (Doutorado em Direitos e Garantias Fundamentais), Faculdade de Direito de Vitória (FDV). Disponível em: http://site.fdv.br/wpcontent/uploads/2018/06/claudio-de-oliveira-santos-colnago.pdf. Acesso em: 29 fev. 2020.

DEBORD, Guy. Sociedade do espetáculo. Rio de Janeiro: Contraponto, 2003. Disponível em: https://www.marxists.org/portugues/debord/1967/11/sociedade.pdf. Acesso em: 30 set. 2019.

FARIAS, Edilsom Pereira de. Liberdade de Expressão e Comunicação: teoria e proteção constitucional. 2001. 290 f. Monografia (Pós-graduação em Direito) - Universidade Federal de Santa Catarina, Florianópolis, 2001. Disponível em:

https://repositorio.ufsc.br/xmlui/bitstream/handle/123456789/79426/182787.pdf?sequence=1 \&isAllowed=y. Acesso em: 17 out. 2019.

FERNANDES, Bernardo Gonçalves. Curso de direito constitucional. 3. ed. Rio de Janeiro: Lumen Juris, 2011. 
OLIVEIRA, Antonio Leal de; NASCIMENTO, Carolina Rondelli do; FRAGA, Carolina Marcondes. Os limites à liberdade de expressão na era da (des)informação: novas fronteiras e perspectivas para a efetivação dos direitos fundamentais

FREITAS, Riva Sobrado de; DE CASTRO, Matheus Felipe. Liberdade de Expressão e Discurso do Ódio: um exame sobre as possíveis limitações à liberdade de expressão. Scielo, Florianópolis, n. 66, p. 327-355, jul. 2013. DOI: https://doi.org/10.5007/2177-

7055.2013v34n66p327. Disponível em: http://www.scielo.br/pdf/seq/n66/14.pdf. Acesso em: 16 out. 2019.

G1. Não é normal você ser julgada por causa de sua aparência', diz Cleo sobre ataque nas redes. Fantástico, São Paulo, 06 out. de 2019. Acesso em: 24 mar. 2020

POPPER, Karl Raimund. The open society and its enemies. Nova Jérsei: Princeton, 1971.

SARMENTO, Daniel. A liberdade de Expressão e o Problema do "Hate Speech". In:

FARIAS, Cristiano Chaves de (org.). Leituras Complementares de Direito Civil. 2. ed. São Paulo: Juspodivm, 2009. Acesso em: 15 out. 2019.

SILVA, Rosana Leal da; BOLZAN, Bárbara Eleonora Taschetto; CIGANA, Paula Fabíola. A Liberdade de Expressão e seus Limites na Internet: uma análise a partir da perspectiva da organização dos Estados americanos. R. Dir. Gar. Fund., Vitória, v. 20, n. 1, p. 219-250, jan./abr. 2019. Disponível em:

http://sisbib.emnuvens.com.br/direitosegarantias/article/view/1092/pdf. Acesso em: 16 out. 2019.

TÔRRES, Fernanda Carolina. O Direito Fundamental à Liberdade de Expressão e sua Extensão. Revista de Informação Legislativa, v. 50, n. 200, p. 61-80, out./dez. 2013. Disponível em: https://www12.senado.leg.br/ril/edicoes/50/200/ril_v50_n200_p61.pdf. Acesso em: 18 out. 2019. 